УДК 621.793 .722

DOI: 10.34220/2311-8873-2020-3-3-140-142

ИМПУЛЬСНАЯ МОДУЛЯЦИЯ КАК СПОСОБ ПОВЫШЕНИЯ КАЧЕСТВА ПЛАЗМЕННЫХ ПОКРЫТИЙ

Кадырметов А.М., Бухтояров В.Н., Попов П.Н.

Федеральное государственное бюджетное образовательное учреждение высшего образования «Воронежский государственный лесотехнический университет им. Г.Ф. Морозова»

E-mail: $79081469891 @$ yandex.ru

Аннотация: В статье рассматриваются способы импульсной модуляции электрических параметров при плазменном напылении. Рассматриваются достоинства и недостатки модуляции.

Ключевые слова: импульсная модуляция, плазменные покрытия, свойства покрытий.

\title{
PULSE MODULATION AS A WAY TO IMPROVE THE QUALITY OF PLASMA COATINGS
}

Kadyrmetov A.M., Buhtoyarov V.N., Popov P.N.

Federal State Budgetary Educational Institution of Higher Education «Voronezh State Forestry University. G.F. Morozova»

E-mail: $79081469891 @$ yandex.ru

Summary: The article discusses methods for pulse modulation of electrical parameters during plasma sputtering. The advantages and disadvantages of modulation are considered.

Keywords: pulse modulation, plasma coatings, coating properties.

В последнее время уделяется большое внимание долговечности деталей. Причем ресурс деталей и всего агрегата должен быть одинаковым. Поэтому основной задачей при изготовлении и проектировании деталей машин является повышение их долговечности. Для повышения долговечности могут быть применимы гальваническое наращивание, различного рода наплавки, напыление металла.

Определенное положение в машиностроении занимает газотермическое нанесение металла, плазменная наплавка, плазменная закалка, финишное плазменное упрочнение, разные способы нанесения покрытий. 
Напыление металла возможно с помощью различных способов газотермического напыления, которое включает в себя плазменное, детонационное, газопламенное. Плазменное напыление имеет один, но значительный недостаток - низкая прочность соединения покрытия и материала детали. Для того что бы этот недостаток устранить различными авторами предлагается много способов повышающих эксплуатационных характеристик покрытий.

Для повышения качества плазменных покрытий возможно применение следующих методов: пластическое деформирование покрытий, оплавление плазменных покрытий в вакууме, обработка давлением в газостатах, использование силы взрыва, оплавление газовой горелкой или плазменным потоком, лучевые способы оплавления, магнитоимпульсная и ультразвуковая электроконтактная обработка.

Имеющиеся особенности физико-механических свойств плазменных покрытий, показывают, что для повышения их качества применимы методы, которые условно можно разбить на две группы: термического воздействия оплавления покрытия за счет различных источников тепла; термомеханический - одновременное оплавление и пластическая обработка $[1,2]$.

Использование термомеханических способов повышает прочность соединения покрытия с деталью приблизительно до 30 \% в сравнении с традиционным плазменным напылением. Использование термического воздействия позволяет получать по своей сути монолитное соединение между покрытием и материалом детали. Но существенным недостатком, является перегрев детали, что может привести к изменению физико-механических свойств материала, и как следствие прочностных характеристик самой детали.

В Санкт-петербургском государственном политехническом университете активно проводят исследования и разработку плазменных технологий. Данная организация разработала напыление-наплавку, плазменное финишное упрочнение, постоянно ведет исследование разных плазменных технологий [3-5].

Применение плазменной наплавки на обратной полярности (подключение детали осуществляется к отрицательному полюсу источника питания) способствует устранению непровары, образования трещин, пор, отслоения покрытия от основного материала, минимизируется зона термического влияния. Не смотря на наличие большого количества достоинств возникают и недостатки:

1) снижается ресурс деталей плазматрона;

2) не устойчивое горение прямой дуги; 
3) ряд металлов, образующие соединения, обладающие большей эмиссией электронов, чем сам обрабатываемый металл, могут затруднить плазменную обработку из-за снижения стабильности сжатой дуги обратной полярности;

4) габаритные размеры плазматрона ограничивают его применения для различного вида деталей.

В работе предлагается использовать импульсную модуляцию позволяющую осуществлять наложения импульсов тока или напряжения на стационарный ток дуги обратной полярности (рис. 1).

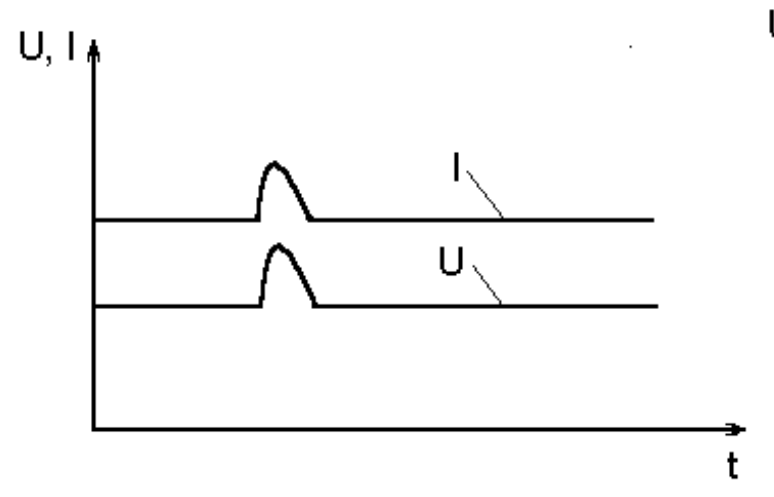

$a$

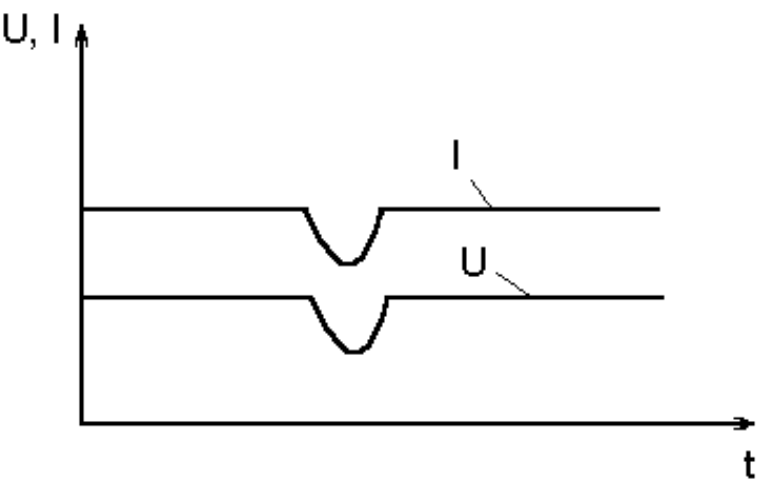

$\sigma$

$a$ - положительная модуляция; $\sigma$ - отрицательная модуляция

Рисунок 1 - Осциллограммы силы тока I и напряжения $U$

В процессе нанесения покрытия на стационарный ток могут быть наложены положительные и отрицательные импульсы силы тока. В зависимости от значения импульсы, либо повышают или понижают среднее значение электрической мощности. С использованием данной методики можно регулировать подвод тепла к детали. Положительные импульсы кратковременно, доли секунды воздействуют на покрытие. Стационарное значение электрической мощности в данном случае имеет минимальное значение, что бы оплавить покрытие, а импульсы приплавляют покрытие к основному материалу. При отрицательных импульсах, мощность стационарной дуги достаточна для оплавления и приплавления покрытия, но деталь подвержена перегреву, импульсы снижают среднее значение мощности плазматрона.

Электрическая дуга представляет собой направленное движение электронов. Электроны бомбардируя поверхность повышают температуру поверхности и разрушают ее, особенно это проявляется при обратной полярности. Применяя импульсы силы тока и напряжения, они заставят двигаться в обратном направлении электроны. Регулируя мощность импульсов и частоту модуляции можно 
распределить равномерно температуру между электродами и обеспечить равномерную их эрозию.

Стабильность дуги в основном определяется дистанцией между поверхностями. Если при стационарной дуге привязка дуги будет осуществляться по выступам неровностей поверхности, то использование модуляции повышает стабильность горения дуги, так как импульс уверенно пробивает воздушный промежуток.

Перечисленные достоинства говорят об эффективности применения модуляции электрических параметров при различных плазменных технологиях. В то же время, возникает необходимость научного обоснования эффективности использования модуляции электрических параметров [6].

\section{СПИСОК ЛИТЕРАТУРЫ}

1 Кадырметов, А. М. Теоретические основы и технологическое обеспечение качества плазменного нанесения и упрочнения покрытий модуляцией электрических параметров : автореф. дис. ... докт. техн. наук : 05.02.07, 05.02. 08 / А. М. Кадырметов ; ВГЛТА. - Воронеж, 2013. - 32 с.

2 Кадырметов, А. М. Управление технологическим обеспечением процессов плазменного нанесения покрытий в режиме модуляции электрических параметров / А. М. Кадырметов. - Воронеж : Издательскополиграфический центр «Научная книга», 2013. - 260 с.

3 Соснин, Н. А. Плазменные технологии. Руководство для инженеров / Н. А. Соснин, С. А. Ермаков, П. А. Тополянский. - СПб : Изд-во Политехн. ун-та. $-2008 .-406$ c.

4 Тополянский, П. А. Плазменные технологии нанесения покрытий / П. А. Тополянский // Сварщик № 3, 2002 г. - С. 10-11.

5 Соснин, Н. А. Плазменные технологии / Руководство для инженеров / Н. А. Соснин, С. А. Ермаков, П. А. Тополянский, СПб : Из-во Политехн. ун-та, 2008. $-408 \mathrm{c}$.

6 Kadyrmetov, A. M. Features of thermal processes of plasma deposition and hardening of coatings with external modulation parameters of the arc / A. M. Kadyrmetov, S. N. Sharifullin, A. F. Maltsev // IOP Conference Series: Materials Science and Engineering. - 2016. - V. 134. - 012009. - pp. 1-7. / http://iopscience.iop.org/article/10.1088/1757-899X/134/1/012009/pdf. 